\title{
CCND1 G870A polymorphism and colorectal cancer risk: An updated meta-analysis
}

\author{
XIAO-MING XU ${ }^{1,2^{*}}$, XIAO-BING NI ${ }^{1,2^{*}}$, GONG-LI YANG ${ }^{2}$, ZHI-GUO LUO ${ }^{3}$, YU-MING NIU ${ }^{1,2}$ and MING SHEN ${ }^{4}$ \\ Departments of ${ }^{1}$ Stomatology and Center for Evidence-Based Medicine and Clinical Research, ${ }^{2}$ Gastroenterology \\ and ${ }^{3}$ Clinical Oncology, Taihe Hospital, Hubei University of Medicine, Shiyan, Hubei 442000; \\ ${ }^{4}$ Jiangsu Key Laboratory of Oral Diseases, Department of Dental Implant, Affiliated Hospital \\ of Stomatology, Nanjing Medical University, Nanjing, Jiangsu 210029, P.R. China
}

Received October 12, 2015; Accepted March 10, 2016

DOI: $10.3892 / \mathrm{mco} .2016 .844$

\begin{abstract}
Molecular epidemiological studies have revealed a closer association between cyclin D1 (CCND1) polymorphism and the risk of colorectal cancer; however, the results were inconsistent. The aim of the present meta-analysis was to investigate the association between CCND1 G870A polymorphism and colorectal cancer risk. Online electronic databases (PubMed and Embase) were searched. Odds ratios (ORs) with $95 \%$ confidence intervals (CIs) were calculated to assess the association between CCND1 G870A polymorphism and the risk of colorectal cancer. In addition, heterogeneity, publication bias and sensitivity analysis were performed to guarantee the statistical power. In total, 23 published case-control studies with 6,320 patients and 8,252 controls were selected. Significantly increased risks were observed in four genetic models (A vs. $\mathrm{G}$ : $\mathrm{OR}=1.09,95 \% \mathrm{CI}=1.00-1.18, I^{2}=54.3 \%$; GA vs. GG: $\mathrm{OR}=1.13,95 \% \mathrm{CI}=1.04-1.24, I^{2}=18.2 \%$; AA vs. $\mathrm{GG}, \mathrm{OR}=1.17$ : 95\% CI=1.00-1.38, $I^{2}=52.5 \%$; GA+AA vs. GG: $\mathrm{OR}=1.14$, $95 \% \mathrm{CI}=1.05-1.24, I^{2}=33.8 \%$ ). Similarly, significant associations were also identified in the stratified analysis in the cancer subtype of sporadic colorectal cancer (GA vs. GG: OR=1.21, 95\% $\mathrm{CI}=1.04-1.42, I^{2}=24.1 \%$; $\mathrm{GA}+\mathrm{AA}$ vs. $\mathrm{GG}: \mathrm{OR}=1.18$, $95 \% \mathrm{CI}=1.02-1.37, I^{2}=35.0 \%$ ), Caucasian population (GA vs. $\mathrm{GG}, \mathrm{OR}=1.14,95 \% \mathrm{CI}=1.02-1.28, I^{2}=19.8 \%$; GA+AA vs. GG,
\end{abstract}

Correspondence to: Dr Yu-Ming Niu, Department of Stomatology and Center for Evidence-Based Medicine and Clinical Research, Taihe Hospital, Hubei University of Medicine, 32 South Renmin Road, Shiyan, Hubei 442000, P.R. China

E-mail:n4oneone@126.com

Dr Ming Shen, Jiangsu Key Laboratory of Oral Diseases, Department of Dental Implant, Affiliated Hospital of Stomatology, Nanjing Medical University, 140 Hanzhong Road, Nanjing, Jiangsu 210029, P.R. China

E-mail: mingshen85@yahoo.com

*Contributed equally

Key words: cyclin D1, polymorphism, colorectal cancer
$\mathrm{OR}=1.14,95 \% \mathrm{CI}=1.02-1.27, I^{2}=37.5 \%$ ) and other subgroups of control design and genotyping type. The present updated meta-analysis suggested that CCND1 G870A may present an increased risk for developing colorectal cancer, particularly in sporadic colorectal cancer and a Caucasian population.

\section{Introduction}

Colorectal cancer is one of the most common malignant diseases. In 2009, there were 146,970 new patients and 49,920 mortalities in the United States, with colorectal cancer ranking third overall in terms of incidence and mortality in men and women (1). Colorectal cancer is a multifactorial disease, resulting from complex interactions between environmental factors and genetic mutations. A number of studies have revealed that diet may be involved in the development of colorectal cancer $(2,3)$. The abnormal intake of animal meat, fat, vegetables and vitamins may increase the risk of development of colorectal cancer. In addition, family history and genetic factors are also closely associated with colorectal cancer; for example, MutS homolog 2 (MSH2) and MutL homolog 1 (MLH1) gene mutations are associated with hereditary non-polyposis colorectal cancer (3).

Aberrant cellular proliferation is closely associated with the development of cancers. The cyclin family is considered to exert a key role in cell proliferation. Cyclin D1 (CCND1) is a major regulator protein, which fulfills a critical role during transition from the growth $(\mathrm{G}) 1$ to the synthesis $(\mathrm{S})$ phase, promoting the progression of the cell cycle during cell mitosis by adhering to cyclin-dependent kinases (CDKs) 4 and $6(4,5)$. The constitutively increased expression of CCND1 is observed in numerous malignant cancers, and is associated with a poor prognosis (6-8).

Single nucleotide polymorphisms (SNPs) are able to change the structure of the genome and influence protein expression and function, which leads to abnormal cell proliferation and an increased risk of cancer (9). The most common mutation locus of the CCND1 gene is at codon 242, with a nucleotide change from guanine $(G)$ to adenine (A) in exon 4 . The A allele increases the frequency of alternative splicing during cell transcription, leading to an elevated level of CCND1, and consequently resulting in abnormal cell proliferation and an escape from apoptosis (10). 
In 2009, Kong et al (11) reported the first case-control study on the CCND1 G870A polymorphism and colorectal cancer risk, but no significant differences in genotyping were observed in a population in the United States. To date, several molecular epidemiological investigations have been performed to evaluate the association between the CCND1 G870A polymorphism and colorectal cancer susceptibility, although the results were inconsistent. In the present investigation, a meta-analysis of published case-control studies was therefore performed to precisely assess the association between the CCND1 G870A polymorphism and the risk of colorectal cancer.

\section{Materials and methods}

This meta-analysis was designed according to the guidelines of the Preferred Reporting Items for Systematic Reviews and Meta-analyses (PRISMA Compliant) statement (12).

Search strategy. A comprehensive online search of the PubMed and Embase databases was performed for studies published up to June 12015 using the following search terms: 'CCND1', 'cyclin D1', 'colorectal cancer', 'colon cancer', 'rectum cancer' and 'polymorphism'. Additional studies were searched for from the references of the retrieved studies, or from review articles on this topic. The following criteria were used to include identified studies in this meta-analysis: (i) a case-control study of the CCND1 G870A polymorphism and colorectal cancer risk; and (ii) sufficient data for estimating odds ratios (ORs) with $95 \%$ confidence intervals (CIs). In cases of partly or completely overlapping data, only the latest study, or the study with the larger sample, was included $(13,14)$.

Data extraction. The following data were extracted from all selected studies independently by two investigators (Xiao-Ming $\mathrm{Xu}$ and Xiao-Bing Ni): the first author's name, publication data, country origin, racial descent of the study population (Asian, Caucasian or mixed), sources of the controls, genotype distribution, genotyping methods, adherence to the Hardy-Weinberg equilibrium (HWE), minor allele frequency (MAF) in controls, and tumor subtypes.

Statistical analysis. Five genotype models were evaluated based on ORs and 95\% CIs to assess the potential association between CCND1 G870A polymorphisms and the risk of colorectal cancer: An allele contrast model (A vs. G), a pair of co-dominant models (AA vs. GG and GA vs. GG), a dominant model (GA+AA vs. GG) and a recessive model (AA vs. GG+GA). Subgroup analyses were performed according to ethnicity and control design. The study heterogeneity was assessed using Cochran's Q statistic and the $I^{2}$ statistic (15). ORs were pooled using a random effects model with the inverse variance (I-V) method (or the DerSimonian and Laird method) when statistical heterogeneity was identified to exist $\left(\mathrm{P}<0.10\right.$ or $\left.I^{2}>50 \%\right)$ (16); otherwise, a fixed effects model (the Mantel-Haenszel method) was adopted (17).

Funnel plots and Egger's linear regression method were used to assess any possible publication bias (18). Cumulative meta-analyses were also performed to identify possible trends in the pooled estimate according to the publication year (19).

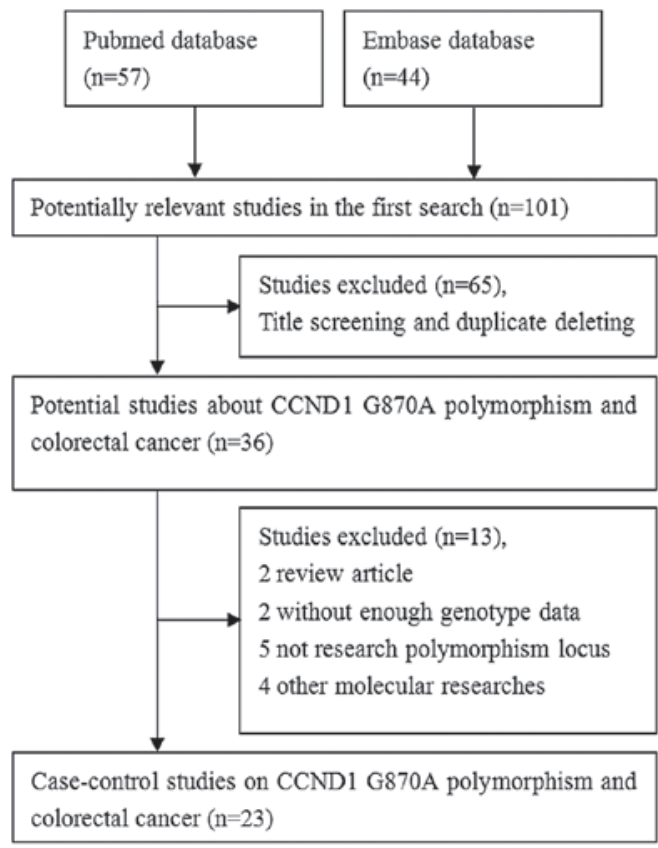

Figure 1. Flow diagram of the study selection process. CCND1, cyclin D1.

All statistical analyses were performed using Stata ${ }^{\circledR}$ version 11.0 (Stata Corporation, College Station, TX, USA). A two-sided $\mathrm{P}<0.05$ was considered to indicate a statistically significant value.

\section{Results}

Study characteristics. A total of 101 associated studies were searched. During the first step, while screening the title and screening for duplicates, 65 studies were excluded. Of the remaining 36 articles, 13 were excluded since two were reviews, two did not include sufficient genotype data, five were not focused on the polymorphism locus, and four were on other molecular studies. The flow chart of study selection is shown in Fig. 1. Ultimately, 23 published case-control studies met the inclusion criteria, including 6,320 patients with colorectal cancer and 8,352 controls (11,20-41). The genotype distribution in each study is shown in Table I. The diverse genotyping methods included polymerase chain reaction-restriction fragment length polymorphism (PCR-RFLP), PCR-single strand conformation polymorphism, PCR Sequenase ${ }^{\mathrm{TM}}$ and TaqMan ${ }^{\circledR}$. Overall, the MAF in controls ranged between 0.412 and 0.614 in Caucasians, and between 0.182 and 0.634 in Asians. In only one study did the control population significantly deviate from the HWE (29).

Meta-analysis. The evaluation of the association between CCND1 G870A polymorphisms and colorectal cancer risk is shown in Table II. Overall, four of the genetic models revealed that the CCND1 G870A polymorphism was significantly associated with an increased risk of colorectal cancer (A vs. G, OR=1.09, 95\% CI=1.00-1.18, $I^{2}=54.3 \%$; $\mathrm{GA}$ vs. $\mathrm{GG}, \mathrm{OR}=1.13,95 \% \mathrm{CI}=1.04-1.24, I^{2}=18.2 \%$; AA vs. $\mathrm{GG}, \mathrm{OR}=1.17,95 \% \mathrm{CI}=1.00-1.38, I^{2}=52.5 \%$; and $\mathrm{GA}+\mathrm{AA}$ vs. $\mathrm{GG}, \mathrm{OR}=1.14,95 \% \mathrm{CI}=1.05-1.24, I^{2}=33.8 \%$; Fig. 2). Similarly, significant risk effects were detected in the 


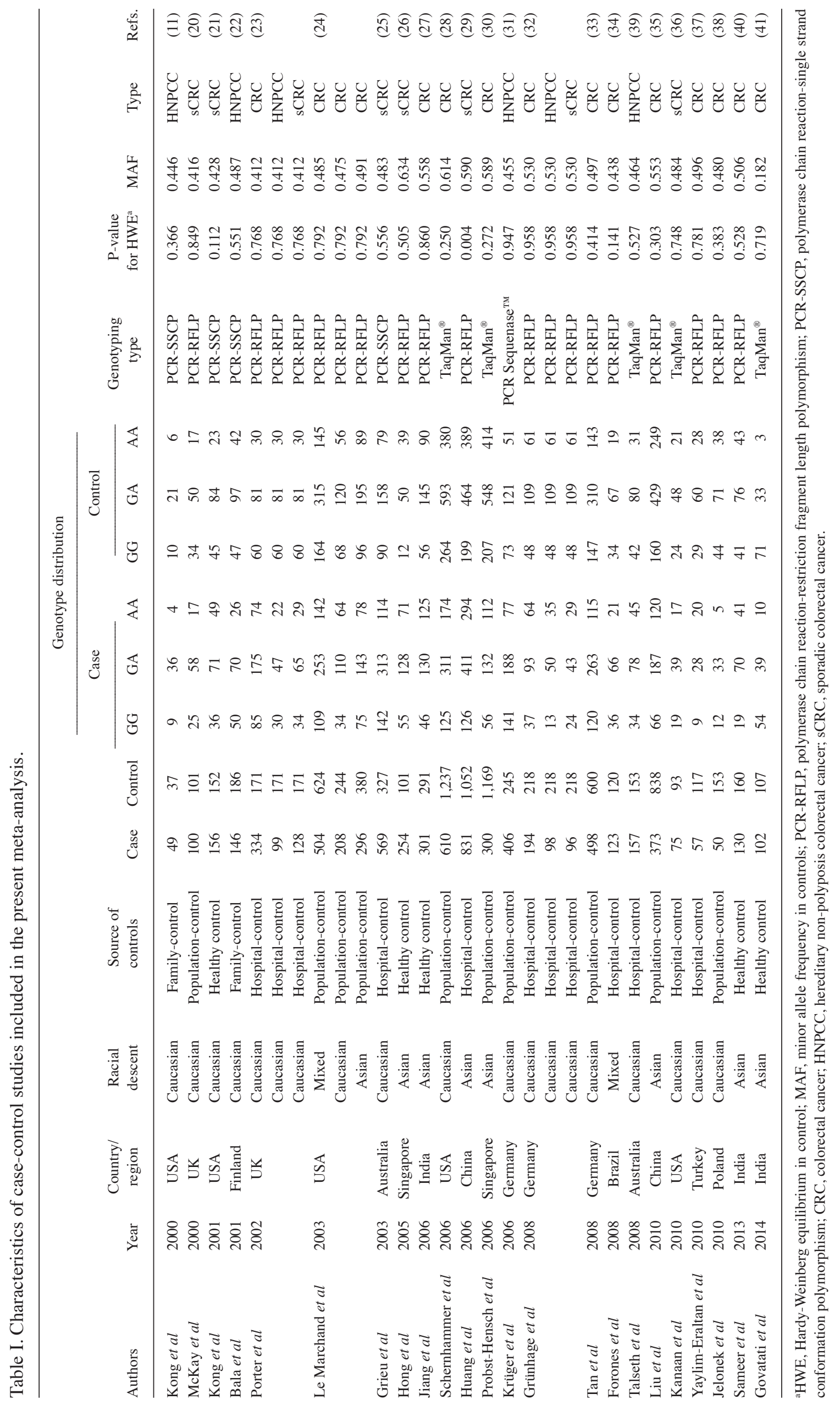




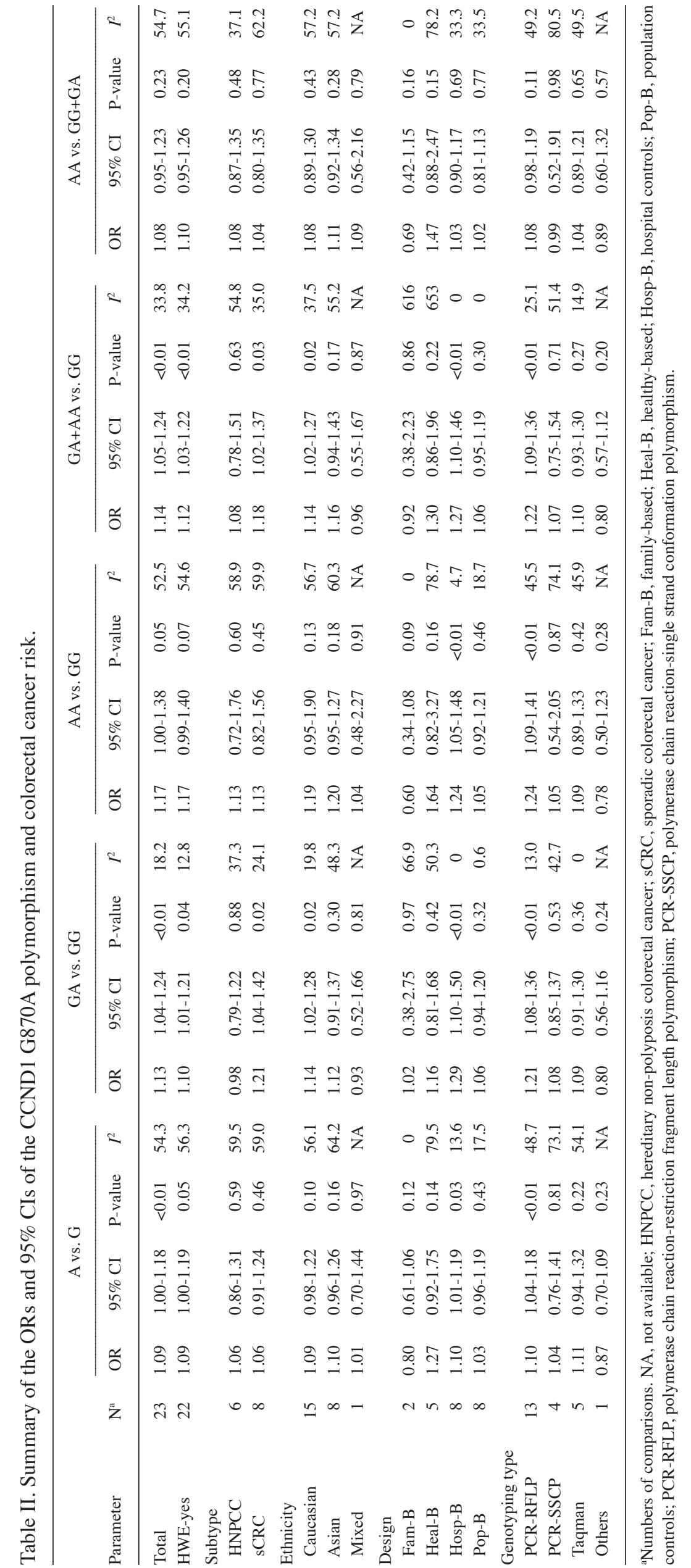




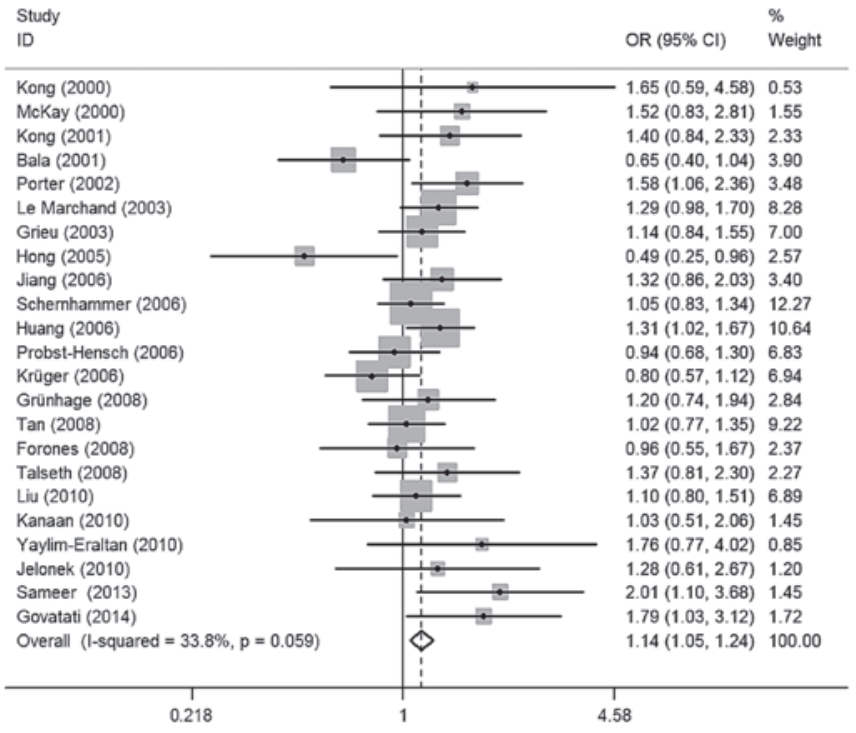

Figure 2. ORs and $95 \%$ CIs for the association between the CCND1 G870A polymorphism and colorectal cancer risk in the GA+AA vs. GG model. CCND1, cyclin D1; OR, odds ratio; CI, confidence interval.

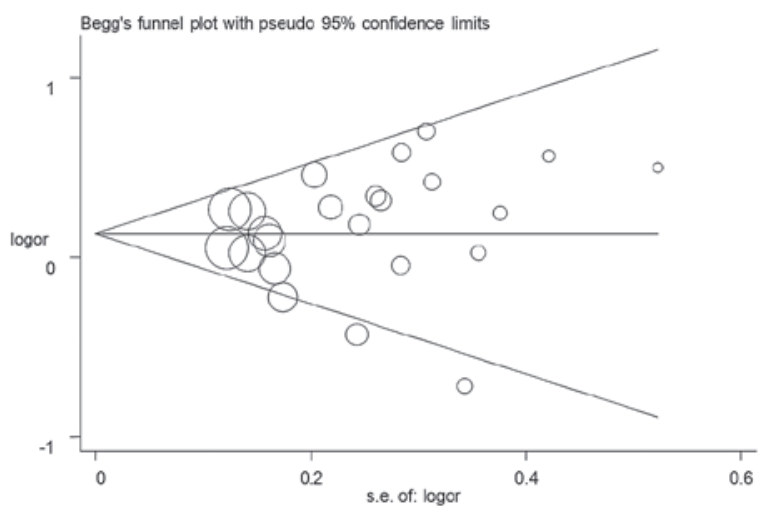

Figure 3. Funnel plot analysis to detect publication bias for the GA+AA vs GG model of the CCND1 G870A polymorphism and colorectal cancer risk. or, odds ratio; s.e., standard error; CCND1, cyclin D1.

subgroup analysis of patients with sporadic colorectal cancer (GA vs. GG, OR=1.21, 95\% CI=1.04-1.42, $I^{2}=24.1 \%$; GA+AA vs. $\mathrm{GG}, \mathrm{OR}=1.18,95 \% \mathrm{CI}=1.02-1.37, I^{2}=35.0 \%$ ) and Caucasians (GA vs. GG, OR=1.14, 95\% CI=1.02-1.28, $I^{2}=19.8 \%$; GA+AA vs. GG, OR=1.14, 95\% CI=1.02-1.27, $I^{2}=37.5 \%$ ). Significantly increased risks were also detected in the stratified analysis of hospital-based studies and studies employing the PCR-PRFLP genotyping method (Table II).

Publication bias. No publication bias was detected in any of the five genetic models. The shape of the funnel plots appeared to be symmetrical for all models (the GA+AA vs. GG model is shown in Fig. 3), and Egger's test results supported these findings (for A vs. $\mathrm{G}$ : $\mathrm{P}=0.34$; for $\mathrm{GA}$ vs. $\mathrm{GG}$ : $\mathrm{P}=0.67$; for AA vs. GG: $\mathrm{P}=0.53$; for $\mathrm{AA}+\mathrm{GA}$ vs. $\mathrm{GG}$ : $\mathrm{P}=0.47$; and for AA vs. $\mathrm{GG}+\mathrm{GA}$ : $\mathrm{P}=0.49$ ).

Sensitivity analysis and cumulative analysis. Sensitivity analyses were performed, and the exclusion of no single study qualitatively changed the pooled ORs, indicating that the

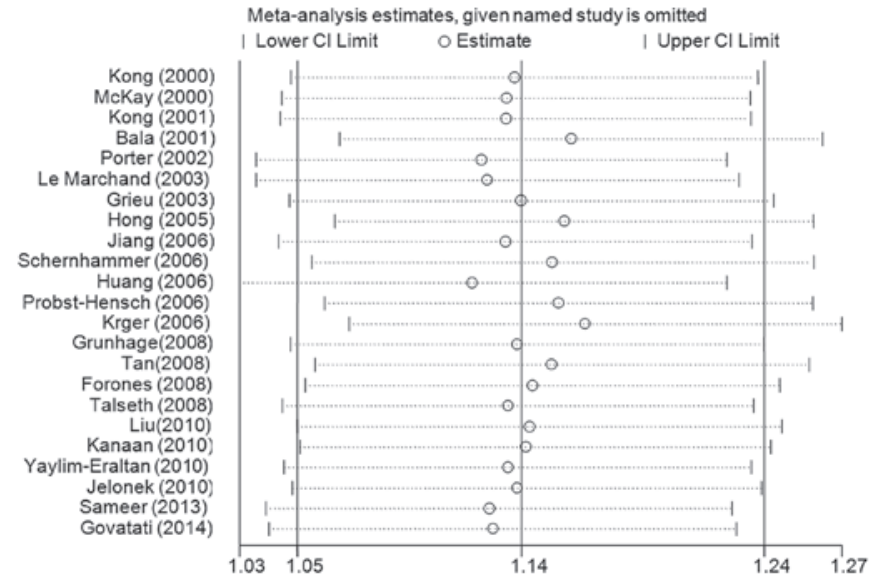

Figure 4 . Sensitivity analysis through deleting each study to reflect the influence of the individual data-set to the pooled ORs in the GA+AA vs. GG model of the CCND1 G870A polymorphism and colorectal cancer risk. OR, odds ratio; $\mathrm{CI}$, confidence interval; CCND1, cyclin D1.

\begin{tabular}{|c|c|c|}
\hline \multicolumn{2}{|l|}{$\begin{array}{l}\text { Study } \\
\text { ID }\end{array}$} & \multirow{2}{*}{$\begin{array}{l}\text { OR }(95 \% \mathrm{Cl}) \\
0.74(0.16,3.50)\end{array}$} \\
\hline Kong (2000) & & \\
\hline McKay (2000) & - & $1.18(0.56,2.48)$ \\
\hline Kong (2001) & ــ & $1.86(1.14,3.03)$ \\
\hline Bala (2001) & 5 & $1.20(0.82,1.75)$ \\
\hline Porter (2002) & . & $1.36(1.00,1.85)$ \\
\hline Le Marchand (2003) & $\rightarrow$ & $1.41(1.12,1.77)$ \\
\hline Grieu (2003) & $\rightarrow$ & $1.26(1.04,1.54)$ \\
\hline Hong (2005) & $\leftarrow$ & $1.16(0.96,1.40)$ \\
\hline Jiang (2006) & $\rightarrow$ & $1.22(1.03,1.45)$ \\
\hline Schernhammer (2006) & 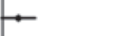 & $1.14(0.99,1.32)$ \\
\hline Huang (2006) & $\rightarrow$ & $1.15(1.01,1.31)$ \\
\hline Probst-Hensch (2006) & $\leftarrow$ & $1.14(1.01,1.28)$ \\
\hline Krüger (2006) & $\leftarrow$ & $1.11(0.98,1.25)$ \\
\hline Grünhage (2008) & + & $1.12(1.00,1.25)$ \\
\hline $\operatorname{Tan}(2008)$ & $\leftarrow$ & $1.10(0.99,1.23)$ \\
\hline Forones (2008) & + & $1.10(0.99,1.23)$ \\
\hline Talseth (2008) & $\leftarrow$ & $1.12(1.00,1.24)$ \\
\hline Liu (2010) & & $1.12(1.01,1.24)$ \\
\hline Kanaan (2010) & + & $1.12(1.01,1.24)$ \\
\hline Yaylim-Eraltan (2010) & $\rightarrow$ & $1.13(1.02,1.25)$ \\
\hline Jelonek (2010) & & $1.12(1.01,1.24)$ \\
\hline Sameer (2013) & $\rightarrow$ & $1.14(1.03,1.25)$ \\
\hline Govatati (2014) & $\rightarrow$ & $1.15(1.04,1.27)$ \\
\hline 0.157 & 1 & 38 \\
\hline
\end{tabular}

Figure 5. Cumulative meta-analyses according to publication year in the GA+AA vs. GG model of the CCND1 G870A polymorphism and colorectal cancer risk. OR, odds ratio; CI, confidence interval; CCND1, cyclin D1.

results of the present meta-analysis were stable (the data for the GA+AA vs. GG model is shown in Fig. 4). Cumulative analyses according to the publication date revealed that the cancer risk increased gradually, and became positive, on inclusion of the study conducted by Talseth et al (39) in 2008 (the GA+AA vs. GG model is shown in Fig. 5).

\section{Discussion}

CCND1 is located on chromosome 11q13, and encodes a critical cell cycle regulatory protein of 295 amino acids. CCND1 regulates the transition from the G1 to the $\mathrm{S}$ phase during cell division. High levels of activity of CCND1 result in premature cell passage through the G1-S transition, leading to an extension of non-repaired DNA damage and the accumulation of genetic mistakes (42). Overexpression of CCND1 has been 
detected in several cancer types, which is also regarded as a risk factor for cancer development. Of the SNPs in CCND1, the G-to-A mutation is the most common, and does not result in an amino acid alteration in the protein sequence. However, the A allele change does lead to an alternatively spliced transcript of CCND1, with a longer half-life compared with the $\mathrm{G}$ allele, which facilitates the passage of the variant cell through the G1-S checkpoint and rapid proliferation, ultimately resulting in cancer development (43). Previous studies have shown that the A allele may be associated with an increased risk of breast, prostate, esophageal and other cancer types in different ethnicities (44-46).

In 2000, the first case-control study performed by McKay et al (20) failed to reveal any significant association between the CCND1 G870A polymorphism and the risk of colorectal cancer in Caucasians. To date, conflicting data about the association between the CCND1 G870A polymorphism and colorectal cancer susceptibility exist. Kong et al (21) identified that the risk of developing colorectal cancer was 3-fold higher in Caucasians with a homozygous A allele $(\mathrm{OR}=2.68$, $95 \% \mathrm{CI}=1.38-5.19)$. The study by Jiang etal (27) suggested that the AA genotype may increase the colorectal cancer risk compared with the $\mathrm{GG}+\mathrm{AG}$ genotype $(\mathrm{OR}=1.56,95 \% \mathrm{CI}=1.10-2.21)$ in an Indian population. Huang et al (29) also identified a significant association between the CCND1 G870A polymorphism and the risk of colorectal cancer in young Chinese patients. Notably, the mechanism of the G870A polymorphism differs according to ethnicity. Porter et al (23) demonstrated an increased risk of familiar colorectal cancer of almost 2-fold (for GA+AA vs. GG: $\mathrm{OR}=1.7,95 \% \mathrm{CI}=1.1-2.7$ ) although the authors did not find any significant association with sporadic colorectal cancer in Caucasians. Le Marchand et al (24) reported a significantly increased risk in Hawaiian individuals with a heterozygous GA genotype $(\mathrm{OR}=3.9,95 \% \mathrm{CI}=1.2-13.2)$, and a marginal risk in Caucasians with a homozygous AA genotype $(\mathrm{OR}=2.1$, 95\% CI=1.0-4.3), although the authors did not find any significant association in a Japanese population. However, the studies by Bala, Schernhammer, Krüger and other research groups $(22,25,28,31,33-36)$ failed to identify any significant association between the CCND1 G870A polymorphism and colorectal cancer. By contrast, several studies revealed that the A allele exerts a protective function in the development of colorectal cancer $(26,30,37,38)$. The present meta-analysis, comprising 23 case control studies with 6,320 patients with colorectal cancer and 8,252 controls, explored the association between an increased risk of colorectal cancer and the CCND1 G870A polymorphism. The findings suggested that CCND1 exerts an important role in the development of colorectal cancer, particularly in Caucasians and in the development of sporadic colorectal cancer.

Several limitations of the present analysis should be acknowledged. First, the results are based on the unadjusted estimates, without the original data from the selected studies, and lack information on certain co-variables, including diet, smoking, drinking and other environmental factors. Secondly, small numbers of patients were included in the cancer subgroups, including cancer location and familiar hereditary, which prevented more precise conclusions from being drawn. The actual association could therefore be biased, and the analysis may not have enough statistical power with the current small sample size. Thirdly, the controls in several of the studies were hospital-based populations with other diseases, which could also result in a certain selection bias. Finally, the majority of the included studies were performed in Caucasian and Asian populations, without any reported studies in African populations; therefore, ethnicity may also result in a certain bias. Despite these limitations, the present meta-analysis included 23 published articles with the largest sample sizes and latest data. A cumulative analysis also demonstrated that the results of our meta-analysis were stable, which further confirm the reliability and validity of the present study.

In conclusion, the present meta-analysis suggested that the CCND1 G870A polymorphism may be associated with an increased risk of the development of colorectal cancer. Considering the limitations due to the small sample size, larger, well-designed case-control studies are required to further validate these findings.

\section{Acknowledgements}

The present study was supported by grant no. D20142102 from the Ministry of Education of Hubei Province.

\section{References}

1. Jemal A, Siegel R, Ward E, Hao Y, Xu J and Thun MJ: Cancer statistics, 2009. CA Cancer J Clin 59: 225-249, 2009.

2. Brevik A, Joshi AD, Corral R, Onland-Moret NC, Siegmund KD, Le Marchand L, Baron JA, Martinez ME, Haile RW, Ahnen DJ, et al: Polymorphisms in base excision repair genes as colorectal cancer risk factors and modifiers of the effect of diets high in red meat. Cancer Epidemiol Biomarkers Prev 19: 3167-3173, 2010.

3. Lynch PM: The hMSH2 and hMLH1 genes in hereditary nonpolyposis colorectal cancer. Surg Oncol Clin N Am 18: 611-624, 2009.

4. Shin MH, Holmes MD, Hankinson SE, Wu K, Colditz GA and Willett WC: Intake of dairy products, calcium and vitamin $\mathrm{d}$ and risk of breast cancer. J Natl Cancer Inst 94: 1301-1311, 2002.

5. Sherr CJ: Cancer cell cycles. Science 274: 1672-1677, 1996.

6. Kaminagakura E, Werneck da Cunha I, Soares FA, Nishimoto IN and Kowalski LP: CCND1 amplification and protein overexpression in oral squamous cell carcinoma of young patients. Head Neck 33: 1413-1419, 2011.

7. Troncone G, Volante M, Iaccarino A, Zeppa P, Cozzolino I, Malapelle U, Palmieri EA, Conzo G, Papotti M and Palombini L: Cyclin D1 and D3 overexpression predicts malignant behavior in thyroid fine-needle aspirates suspicious for Hurthle cell neoplasms. Cancer 117: 522-529, 2009.

8. Abramson VG, Troxel AB, Feldman M, Mies C, Wang Y, Sherman L, McNally S, Diehl A and Demichele A: Cyclin D1b in human breast carcinoma and coexpression with cyclin D1a is associated with poor outcome. Anticancer Res 30: 1279-1285, 2010.

9. Zhang L, Chen LM, Wang MN, Chen XJ, Li N, Huang YD and Chen M: The G894t, T-786c and 4b/a polymorphisms in Enos gene and cancer risk: A meta-analysis. J Evid Based Med 7: 263-269, 2014.

10. Betticher DC, Thatcher N, Altermatt HJ, Hoban P, Ryder WD and Heighway J: Alternate splicing produces a novel cyclin D1 transcript. Oncogene 11: 1005-1011, 1995.

11. Kong S, Amos CI, Luthra R, Lynch PM, Levin B and Frazier ML: Effects of cyclin D1 polymorphism on age of onset of hereditary nonpolyposis colorectal cancer. Cancer Res 60: 249-252, 2000.

12. Moher D, Liberati A, Tetzlaff J and Altman DG: Preferred reporting items for systematic reviews and meta-analyses: The PRISMA statement. BMJ 339: b2535, 2009.

13. Little J, Bradley L, Bray MS, Clyne M, Dorman J, Ellsworth DL, Hanson J, Khoury M, Lau J, O'Brien TR, et al: Reporting, appraising and integrating data on genotype prevalence and gene-disease associations. Am J Epidemiol 156: 300-310, 2002. 
14. Zhang Y, Jia Q, Xue P, Liu Y, Xiong T, Yang J, Song C, He Q and Du L: The-786T $>$ C polymorphism in the NOS3 gene is associated with increased cancer risk. Tumour Biol 35: 3535-3540, 2014.

15. Lau J, Ioannidis JP and Schmid CH: Quantitative synthesis in systematic reviews. Ann Intern Med 127: 820-826, 1997.

16. DerSimonian R and Laird N: Meta-analysis in clinical trials. Control Clin Trials 7: 177-188, 1986.

17. Mantel $\mathrm{N}$ and Haenszel W: Statistical aspects of the analysis of data from retrospective studies of disease. J Natl Cancer Inst 22: 719-748, 1959.

18. Egger M, Davey Smith G, Schneider M and Minder C: Bias in meta-analysis detected by a simple, graphical test. BMJ 315 629-634, 1997.

19. Bagos PG and Nikolopoulos GK: Generalized least squares for assessing trends in cumulative meta-analysis with applications in genetic epidemiology. J Clin Epidemiol 62: 1037-1044, 2009.

20. McKay JA, Douglas JJ, Ross VG, Curran S, Murray GI, Cassidy J and McLeod HL: Cyclin D1 protein expression and gene polymorphism in colorectal cancer. Aberdeen colorectal initiative. Int J Cancer 88: 77-81, 2000.

21. Kong S, Wei Q, Amos CI, Lynch PM, Levin B, Zong J and Frazier ML: Cyclin D1 polymorphism and increased risk of colorectal cancer at young age. J Natl Cancer Inst 93: 1106-1108, 2001.

22. BalaS and Peltomäki P: Cyclin D1 as a genetic modifier in hereditary nonpolyposis colorectal cancer. Cancer Res 61: 6042-6045, 2001.

23. Porter TR, Richards FM, Houlston RS, Evans DG, Jankowski JA Macdonald F, Norbury G, Payne SJ, Fisher SA, Tomlinson I and Maher ER: Contribution of cyclin d1 (CCND1) and E-cadherin (CDH1) polymorphisms to familial and sporadic colorectal cancer. Oncogene 21: 1928-1933, 2002.

24. Le Marchand L, Seifried A, Lum-Jones A, Donlon T and Wilkens LR: Association of the cyclin D1 A870G polymorphism with advanced colorectal cancer. JAMA 290: 2843-2848, 2003.

25. Grieu F, Malaney S, Ward R, Joseph D and Iacopetta B: Lack of association between CCND1 G870A polymorphism and the risk of breast and colorectal cancers. Anticancer Res 23: 4257-4259, 2003

26. Hong Y, Eu KW, Seow-Choen F, Fook-Chong S and Cheah PY: GG genotype of cyclin D1 G870A polymorphism is associated with increased risk and advanced colorectal cancer in patients in Singapore. Eur J Cancer 41: 1037-1044, 2005.

27. Jiang J, Wang J, Suzuki S, Gajalakshmi V, Kuriki K, Zhao Y, Nakamura S, Akasaka S, Ishikawa $H$ and Tokudome S: Elevated risk of colorectal cancer associated with the AA genotype of the cyclin D1 A870G polymorphism in an Indian population. J Cancer Res Clin Oncol 132: 193-199, 2006.

28. Schernhammer ES, Tranah GJ, Giovannucci E, Chan AT, Ma J, Colditz GA, Hunter DJ, Willett WC and Fuchs CS: Cyclin D1 A870G polymorphism and the risk of colorectal cancer and adenoma. Br J Cancer 94: 928-934, 2006.

29. Huang WS, Tang R, Lin PY, Changchien CR, Chen JS, Chiang JM, Yeh CY, Wang JY and Hsieh LL: Impact of the cyclin D1 A870G polymorphism on susceptibility to sporadic colorectal cancer in Taiwan. Dis Colon Rectum 49: 602-608, 2006.

30. Probst-Hensch NM, Sun CL, Van Den Berg D, Ceschi M, Koh WP and Yu MC: The effect of the cyclin D1 (CCND1) A870G polymorphism on colorectal cancer risk is modified by glutathione-S-transferase polymorphisms and isothiocyanate intake in the Singapore Chinese health study. Carcinogenesis 27: 2475-2482, 2006.

31. Krüger S, Engel C, Bier A, Mangold E, Pagenstecher C, Doeberitz Mv, Holinski-Feder E, Moeslein G, Keller G, Kunstmann E, et al: Absence of association between cyclin D1 (CCND1) G870A polymorphism and age of onset in hereditary nonpolyposis colorectal cancer. Cancer Lett 236: 191-197, 2006.
32. Grünhage F, Jungck M, Lamberti C, Berg C, Becker U, Schulte-Witte H, Plassmann D, Rahner N, Aretz S, Friedrichs N, et al: Association of familial colorectal cancer with variants in the E-cadherin (CDH1) and cyclin D1 (CCND1) genes. Int J Colorectal Dis 23: 147-154, 2008.

33. Tan XL, Nieters A, Kropp S, Hoffmeister M, Brenner H and Chang-Claude J: The association of cyclin D1 G870A and E-cadherin C-160A polymorphisms with the risk of colorectal cancer in a case control study and meta-analysis. Int J Cancer 122 : 2573-2580, 2008.

34. Forones NM, de Lima JM, de Souza LG and da Silva ID: Cyclin D1 A870G polymorphism in Brazilian colorectal cancer patients. J Gastrointest Cancer 39: 118-123, 2008.

35. Liu B, Zhang Y, Jin M, Ni Q, Liang X, Ma X, Yao K, Li Q and Chen K: Association of selected polymorphisms of CCND1, p21 and caspase8 with colorectal cancer risk. Mol Carcinog 49: 75-84, 2010.

36. Kanaan Z, Eichenberger MR, Young M, Colliver D, Crawford N, Cobbs GA, Hein DW and Galandiuk S: An alternative cyclin-D1 splice site is not linked to inflammatory bowel disease-associated neoplasia. Int J Biol Markers 25: 27-31, 2010.

37. Yaylim-Eraltan I, Arikan S, Yildiz Y, Cacina C, Ergen HA, Tuna G, Görmüs U, Zeybek U and Isbir T: The influence of cyclin D1 A870G polymorphism on colorectal cancer risk and prognosis in a Turkish population. Anticancer Res 30: 2875-2880, 2010.

38. Jelonek K, Gdowicz-Klosok A, Pietrowska M, Borkowska M, Korfanty J, Rzeszowska-Wolny J and Widlak P: Association between single-nucleotide polymorphisms of selected genes involved in the response to DNA damage and risk of colon, head and neck and breast cancers in a Polish population. J Appl Genet 51: 343-352, 2010.

39. Talseth BA, Ashton KA, Meldrum C, Suchy J, Kurzawski G, Lubinski J and Scott RJ: Aurora-A and Cyclin D1 polymorphisms and the age of onset of colorectal cancer in hereditary nonpolyposis colorectal cancer. Int J Cancer 122: 1273-1277, 2008.

40. Sameer AS, Parray FQ, Dar MA, Nissar S, Banday MZ, Rasool S, Gulzar GM, Chowdri NA and Siddiqi MA: Cyclin D1 G870A polymorphism and risk of colorectal cancer: A case control study. Mol Med Rep 7: 811-815, 2013.

41. Govatati S, Singamsetty GK, Nallabelli N, Malempati S, Rao PS, Madamchetty VK, Govatati S, Kanapuram R, Narayana N, Bhanoori M, et al: Contribution of cyclin D1 (CCND1) and E-cadherin (CDH1) alterations to colorectal cancer susceptibility: A case-control study. Tumour Biol 35: 12059-12067, 2014.

42. Hall $M$ and Peters G: Genetic alterations of cyclins, cyclin-dependent kinases and Cdk inhibitors in human cancer. Adv Cancer Res 68: 67-108, 1996.

43. Solomon DA, Wang Y, Fox SR, Lambeck TC, Giesting S, Lan Z, Senderowicz AM, Conti CJ and Knudsen ES: Cyclin D1 splice variants. Differential effects on localization, RB phosphorylation and cellular transformation. J Biol Chem 278: 30339-30347, 2003.

44. Onay UV, Aaltonen K, Briollais L, Knight JA, Pabalan N, Kilpivaara O, Andrulis IL, Blomqvist $\mathrm{C}$, Nevanlinna $\mathrm{H}$ and Ozcelik H: Combined effect of CCND1 and COMT polymorphisms and increased breast cancer risk. BMC Cancer 8: 6, 2008.

45. Mandal RK and Mittal RD: Are cell cycle and apoptosis genes associated with prostate cancer risk in North Indian population? Urol Oncol 30: 555-561, 2010.

46. Casson AG, Zheng Z, Evans SC, Geldenhuys L, van Zanten SV, Veugelers PJ, Porter GA and Guernsey DL: Cyclin D1 polymorphism (G870A) and risk for esophageal adenocarcinoma. Cancer 104: 730-739, 2005. 